\title{
Influence of RAP and Waste Plastic on Cracking Resistance of Warm SMA Mixes
}

\author{
Varuna $\mathbf{M}^{1, *}$, Bhavani Prasad G', Anjaneyappa Venkateshappa ${ }^{1}$, Amarnath M S ${ }^{2}$ \\ ${ }^{1}$ Department of Civil Engineering, R V College of Engineering, Visvesvaraya Technological University, 560059, Bengaluru, India \\ ${ }^{2}$ Department of Civil Engineering, University Visvesvaraya College of Engineering, Bangalore University, 560056, Bengaluru, India
}

Received September 25, 2021; Revised December 7, 2021; Accepted December 23, 2021

\section{Cite This Paper in the following Citation Styles}

(a): [1] Varuna M, Bhavani Prasad G, Anjaneyappa Venkateshappa, Amarnath M S, "Influence of RAP and Waste Plastic on Cracking Resistance of Warm SMA Mixes," Civil Engineering and Architecture, Vol. 10, No. 1, pp. 79 - 87, 2022. DOI: 10.13189/cea.2022.100107.

(b): Varuna M, Bhavani Prasad G, AnjaneyappaVenkateshappa, Amarnath M S (2022). Influence of RAP and Waste Plastic on Cracking Resistance of Warm SMA Mixes.Civil Engineering and Architecture, 10(1), 79 - 87. DOI: 10.13189/cea.2022.100107.

Copyright $\odot 2022$ by authors, all rights reserved. Authors agree that this article remains permanently open access under the terms of the Creative Commons Attribution License 4.0 International License

\begin{abstract}
Cracking resistance of stone matrix asphalt (SMA) mixes is determined with and without reclaimed asphalt pavement materials (RAP) using coarse aggregates having elongation and flakiness index (EI+FI) of 25 and $35 \%$ respectively. The RAP at varying proportions viz 0 , 10,20 and $30 \%$ were blended with shredded plastic waste (SWP) at dosages of 4, 8, 12 and $16 \%$. Zycotherm is used as warm mix asphalt (WMA) additive. Volumetric properties were determined at optimum binder content using Marshall mix design. Semicircular bending test was carried out to determine cracking resistance. No significant change in fracture resistance was observed for mixes prepared using aggregates having (EI+FI) of 25 and $35 \%$. The strain energy release rate (Jc) for SMA specimen using VG-30 with varied RAP content of 10,20 and $30 \%$ was found to be $0.55,0.58$ and $0.62 \mathrm{kN}-\mathrm{mm}$ respectively. The addition of SWP increased Jc value up to $8 \%$ for hot asphalt SMA mixes. Decrease in Jc was observed for above SMA specimens when prepared using WMA additive. It was observed that addition of WMA enables utilization of SWP up to $12 \%$ and use of SWP in SMA mix prepared with RAP increases resistance to cracking.
\end{abstract}

Keywords Cracking Resistance, Flakiness and Elongation Index, Reclaimed Asphalt Pavement, Shredded Waste Plastic, Stone Matrix Asphalt, Warm Mix Asphalt

\section{Introduction}

The mechanical property of asphalt mixes is influenced by the geometry of aggregates [1-3]. Aggregate geometry is defined by its form, angularity and surface texture [4]. Angularity measures the aggregate roundness that quantifies the shape of the aggregate by its edges [5] and is one of the primary aggregate properties described in the Superpave specifications [1, 6]. Since in SMA, aggregates are arranged to form stone to stone contact, leading to coarse aggregate skeleton, the geometry of aggregates influences pavement rutting and cracking. Fatigue cracking of asphalt mixture depends on aggregate structure, wheel load, test temperature, binder type and quality [7]. The addition of RAP increases fatigue cracking performance of mix $[8,9,10]$. The use of RAP at various percentages in asphalt mixes increased mechanical performance of mix $[11,12]$. The percentage of RAP content could be increased by adding a softer virgin binder, use of gap graded mixes, or using warm mix additive [13]. The Fatigue cracking performance of test track study conducted by NCAT indicated that RAP content up to $45 \%$ can be utilized in open graded mixes whereas $15 \%$ RAP content in dense mixes [14, 15], indicating utilization higher RAP percentages in gap graded mixes. The addition of warm mix asphalt in SMA mix may be a viable option to incorporate higher RAP content as it contains rich binder with less ageing properties and mixes are produced at $30^{\circ} \mathrm{C}$ lower than conventional Hot mixes [16]. Stone matrix asphalt mixes prepared using WMA additives such as FT 
wax and cellulose fibre increased service live of pavement compared to conventional mixes [17]. Waste plastic can be added during road construction either by dry or wet method. In wet process, polymers mixed with hot bitumen, whereas dry process mixed with hot aggregates and then bitumen is added. Addition of recycled or low density poly-ethylene enhances resistance to moisture susceptibility, strength and stiffness of asphalt mix [18-20]. The drain down characteristics, Marshall stability and stiffness increased with addition of waste plastic bottles [21,22]. Similar observation was made $[23,24]$ when waste PET flakes were added into SMA mixes in dry process. Integrating WMA, RAP and waste plastic in asphalt mixes optimizes the advantages towards sustainable pavements.

Several studies focused on utilization RAP and WMA additives at high temperature performance and moisture sensitivity [25] and influence of combined index of aggregates on rutting resistance [26], Very limited studies are carried out on use of waste plastic for warm asphalt mixes. Present study aims to evaluate the cracking resistance of warm SMA mixes with addition of RAP with specific focus on the amount of shredded plastic waste that can be utilized at lower working temperature.

\section{Experimental Work}

Conventional SMA Mix was prepared using aggregates having Elongation Index +Flakiness Index (EI+FI) of 25 and 35\% using VG 30 binder. The RAP materials were blended at varying proportions of 10, 20 and 30\% and shredded waste plastic waste was added as stabilizer at dosage of $4,8,12$, and $16 \%$ by weight of VG 30 binder for above combination. The mixes were prepared using warm mix additive. Marshall mix design was carried out and volumetric properties were determined as per Asphalt Institute MS 2 (Seventh Edition) at $4.0 \%$ air voids level. The present work primarily focused on evaluating fracture resistance of SMA mixes by utilizing shredded plastic waste and RAP for two aggregates shapes, the optimum binder content obtained for above combinations is adopted for mixes prepared with warm mix additive. Critical strain energy release rate, Jc of SMA mix was determined as per ASTM D8044-16 [27] at $25^{\circ} \mathrm{C}$. A Jc value ranging from 0.5 to $0.60 \mathrm{kN}-\mathrm{mm}$ is typically recommended to ensure adequate fracture resistance of mixes.

\section{Materials and Methods}

\subsection{Sphericity}

Sphericity of coarse aggregates is determined as per Equation 1. Sphericity values range from 0.3 to 0.9 where 0 represents non spherical and 1 represents perfect sphere. The particles are classified into four categories as per Zinggshape classes [28] and are shown in Table 1.

Table 1. Zingg shape classes

\begin{tabular}{|c|c|c|c|}
\hline Class & $\mathbf{b} / \mathbf{a}$ & $\mathbf{c} / \mathbf{b}$ & Shape \\
\hline I & $>2 / 3$ & $<2 / 3$ & Oblate (discoidal, tabular) \\
\hline II & $>2 / 3$ & $>2 / 3$ & Equiaxial (spherical, equant) \\
\hline III & $<2 / 3$ & $<2 / 3$ & Triaxial(bladed) \\
\hline IV & $<2 / 3$ & $>2 / 3$ & Prolate(rods) \\
$\qquad$ \\
$\Psi$ & $=\sqrt[3]{\frac{\mathrm{bc}}{\mathrm{a}^{2}}}$
\end{tabular}

Where:

$\Psi=$ Sphericity; $\mathrm{a}, \mathrm{b}$. and $\mathrm{c}$ are the long intermediate and short axis dimensions, respectively.

\subsection{Aggregate Shape}

Shape of the aggregates is determined by flakiness and elongation index and sphericity. In SMA mix, Voids in Uncompacted Aggregates (VCA) indicate aggregate's angularity, sphericity and surface texture (AASHTO 2003) [29]. The EI+FI is determined for sieve slots of $20-16 \mathrm{~mm}$, $16-12.5 \mathrm{~mm}, 12.5-10 \mathrm{~mm}, 10-6.3 \mathrm{~mm}$ and obtained values are shown in Table 2

\subsection{Virgin Aggregates}

Aggregates were collected from two different crushing plants from same source. The elongation index + flakiness index for aggregates obtained from two plants were 25 and 35 respectively. The properties of aggregates of different combined index are presented in Table 3. 
Table 2. Aggregates shape characteristics

\begin{tabular}{|c|c|c|c|c|c|c|c|c|c|c|}
\hline $\begin{array}{l}\text { Size Range } \\
(\mathbf{m m})\end{array}$ & $\begin{array}{c}\text { Aggregate } \\
\text { Type }\end{array}$ & $\begin{array}{c}\text { FI+EI } \\
\%\end{array}$ & $\begin{array}{c}\mathbf{a} \\
(\mathbf{m m})\end{array}$ & $\begin{array}{c}\mathbf{b} \\
(\mathbf{m m})\end{array}$ & $\begin{array}{c}\mathbf{c} \\
(\mathbf{m m})\end{array}$ & $\Psi$ & $\mathbf{c} / \mathbf{b}$ & $\mathbf{b} / \mathbf{a}$ & $\begin{array}{l}\text { Shape as } \\
\text { per Zingg }\end{array}$ & $\begin{array}{l}\text { Standard } \\
\text { Deviation }\end{array}$ \\
\hline \multirow{4}{*}{$20-16$} & Virgin & 16 & 27.3 & 19.5 & 14.2 & 0.72 & 0.73 & 0.71 & Equiaxial & 0.07 \\
\hline & Aggregate & 30 & 31.2 & 22.4 & 9.8 & 0.61 & 0.44 & 0.72 & Oblate & 0.06 \\
\hline & RAP & 18 & 21.2 & 15 & 9.7 & 0.69 & 0.65 & 0.71 & Oblate & 0.09 \\
\hline & Aggregate & 27 & 32.3 & 21.1 & 10.0 & 0.59 & 0.47 & 0.65 & Triaxial & 0.06 \\
\hline \multirow{4}{*}{$16-12.5$} & Virgin & 18 & 22.1 & 16.8 & 11.2 & 0.73 & 0.67 & 0.76 & Equiaxial & 0.05 \\
\hline & Aggregate & 29 & 25.6 & 18.3 & 8.5 & 0.62 & 0.46 & 0.71 & Oblate & 0.09 \\
\hline & RAP & 17 & 19.0 & 13.5 & 8.9 & 0.69 & 0.66 & 0.71 & Equiaxial & 0.10 \\
\hline & Aggregate & 30 & 26.8 & 18.1 & 9.0 & 0.61 & 0.50 & 0.68 & Oblate & 0.09 \\
\hline \multirow{4}{*}{$12.5-10$} & Virgin & 17 & 13.2 & 10.3 & 7.6 & 0.77 & 0.74 & 0.78 & Equiaxial & 0.10 \\
\hline & Aggregate & 29 & 19.6 & 10.5 & 7.9 & 0.60 & 0.75 & 0.54 & Prolate & 0.07 \\
\hline & RAP & 17 & 16.7 & 12.7 & 7.7 & 0.71 & 0.61 & 0.76 & Oblate & 0.04 \\
\hline & Aggregate & 28 & 21.1 & 13.9 & 7.8 & 0.62 & 0.56 & 0.66 & Triaxial & 0.10 \\
\hline \multirow{4}{*}{$10-6.3$} & Virgin & 15 & 13.0 & 9.5 & 7.0 & 0.73 & 0.74 & 0.73 & Equiaxial & 0.08 \\
\hline & Aggregate & 29 & 16.7 & 10.8 & 5.7 & 0.60 & 0.53 & 0.65 & Triaxial & 0.07 \\
\hline & RAP & 17 & 14.7 & 9.2 & 7.9 & 0.70 & 0.86 & 0.63 & Prolate & 0.05 \\
\hline & Aggregate & 29 & 17.8 & 10.4 & 8.1 & 0.64 & 0.78 & 0.58 & Prolate & 0.03 \\
\hline \multirow{4}{*}{$6.3-4.75$} & Virgin & 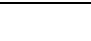 & 9.5 & 5.8 & 4.9 & 0.68 & 0.84 & 0.61 & Prolate & 0.02 \\
\hline & Aggregate & -- & 10.7 & 6.7 & 3.2 & 0.56 & 0.47 & 0.62 & Triaxial & 0.07 \\
\hline & RAP & & 8.9 & 5.4 & 4.5 & 0.67 & 0.83 & 0.61 & Prolate & 0.10 \\
\hline & Aggregate & -- & 11.3 & 5.6 & 4.6 & 0.58 & 0.40 & 0.50 & Triaxial & 0.05 \\
\hline
\end{tabular}

Table 3. Physical properties of conventional aggregates

\begin{tabular}{|c|c|c|c|}
\hline Test Properties & $\begin{array}{c}\text { Conventional } \\
\text { Aggregates- } \\
\text { EI+FI=25 }\end{array}$ & $\begin{array}{c}\text { Conventional } \\
\text { Aggregates- } \\
\text { EI+FI=35 }\end{array}$ & $\begin{array}{c}\text { Requirement } \\
\text { as per MoRTH } \\
\text { Requirement }\end{array}$ \\
\hline Impact value, \% & 15.9 & 17.8 & $<18$ \\
\hline LosAngeles abrasion. \% & 21.4 & 24.0 & $<25$ \\
\hline Specific gravity & 2.66 & 2.67 & $<2$ \\
\hline Water absorption \% & 0.83 & 0.83 & $<$ \\
\hline
\end{tabular}

Table 4. Basic properties of virgin asphalt binder VG 30 and recovered binder

\begin{tabular}{|c|c|c|c|}
\hline Test Properties & VG30 Binder & $\begin{array}{c}\text { Requirement as per } \\
\text { IS 73:2013 }\end{array}$ & Recovered Binder \\
\hline Penetration, mm & 67 & Min.45 & 34 \\
\hline Ductility Test, cm & 92 & Min.70 & 0.580 \\
\hline Softening point, ${ }^{\circ} \mathrm{C}$ & 49 & $45-55$ & 1.02 \\
\hline Kinematic viscosity Pa.s & 0.400 & Min 0.350 & 34 \\
\hline Specific gravity & 1.00 & ---- & \\
\hline
\end{tabular}

\subsection{Virgin Asphalt Binder}

Viscosity Graded Asphalt-30 (VG 30) complying Indian Standard Specification IS 73:2012 [30] is used. The property of asphalt binder is presented in Table 4 .

\subsection{RAP Material}

The RAP material was collected from arterial road section in Bengaluru city, India. The binder was extracted using centrifuge extractor as per ASTM D2172M-11[31] and properties of recovered binder are shown in Table 4. The Flakiness and Elongation index of RAP aggregates were found to be 35 . However, to obtain aggregates of less angular and flaky, RAP aggregates were fed into laboratory jaw crusher and spacing of jaw plates was adjusted by trial-and-error method to obtain Combined Index of 25 . The properties of aggregates of different shape are presented in Table 5. The binder content in RAP was found to be 4.1 and $3.9 \%$ for samples having Flakiness and Elongation index of 25and 35 respectively.

\subsection{Warm Mix Asphalt Additive}

Zycotherm, a commercial chemical additive is used as WMA additive by $0.2 \%$ weight of asphalt binder. 


\subsection{Shredded Waste Plastic}

Shredded waste plasticcontaining polyethylene and polypropylene was supplied by from KK Plastics industry, Bengaluru, India is used passing through $2.36 \mathrm{~mm}$ and retained on $600 \mu$ is used

\subsection{Aggregate Gradation}

SMA binder course prescribed as per Ministry of Road
Transport and Highways, (MoRTH), Government of India V Revision 2013[32] is adopted and gradation is shown in Figure 1.

\subsection{Drain Down}

Drain down test was carried on SMA mix prepared using VG 30 as per IRC SP79:2008[33] and found to be more than $0.3 \%$ for mix prepared with VG 30 binder.

Table 5. Physical properties of conventional aggregates

\begin{tabular}{|c|c|c|c|}
\hline Test Properties & $\begin{array}{c}\text { RAP } \\
\text { Aggregates } \\
\text { EI+FI=25 }\end{array}$ & $\begin{array}{c}\text { RAP } \\
\text { Aggregates } \\
\text { EI+FI=35 }\end{array}$ & $\begin{array}{c}\text { Requirement } \\
\text { as per MoRTH } \\
\text { (2013) }\end{array}$ \\
\hline Impact value (\%) & 15.9 & 18.0 & $<18$ \\
\hline Los Angeles abrasion & 20.4 & 24.5 & $<25$ \\
\hline Specific gravity & 2.66 & 2.67 & - \\
\hline Water absorption (\%) & 0.76 & 0.78 & $<2$ \\
\hline
\end{tabular}

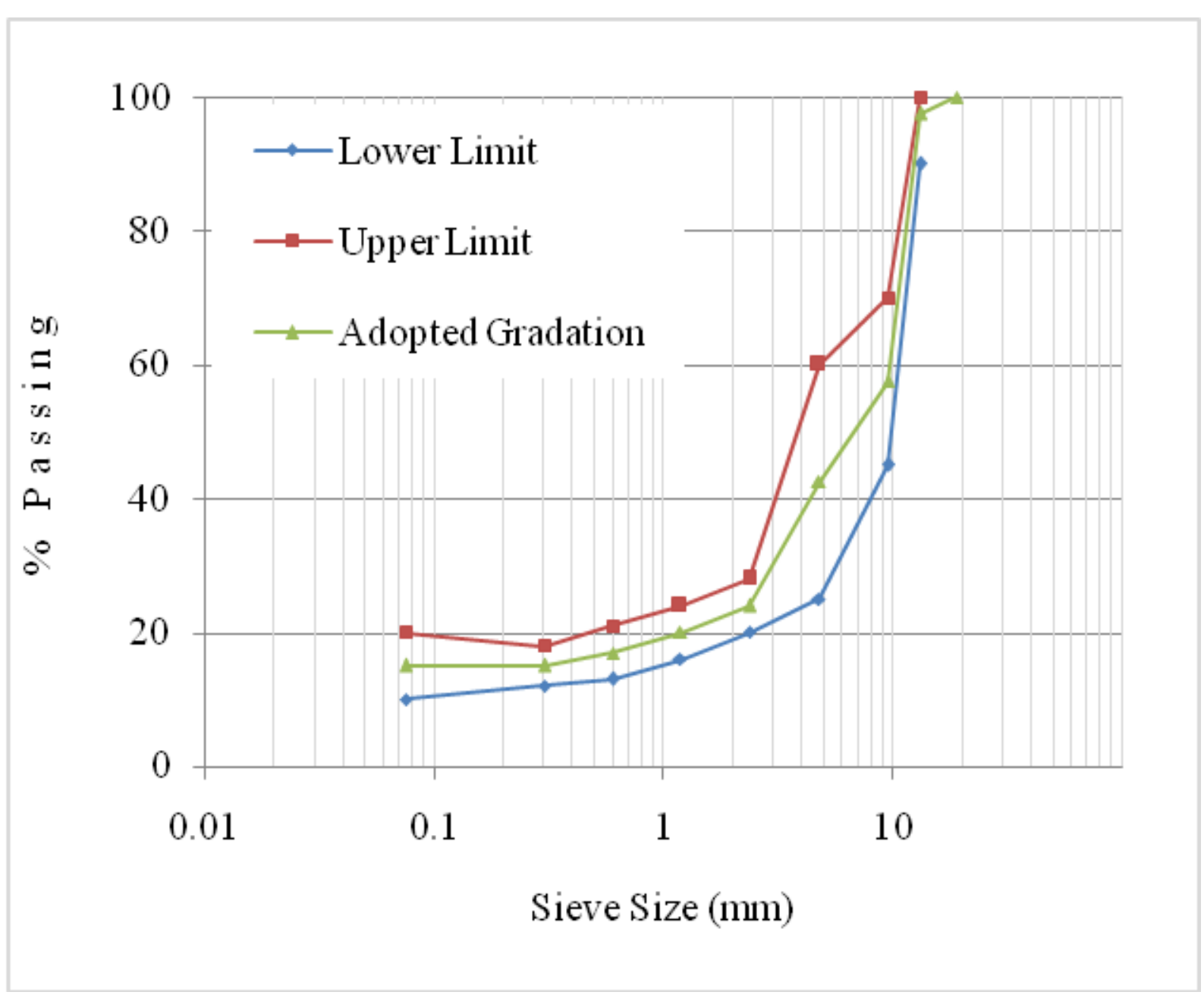

Figure 1. Aggregate gradation for SMA binder course 
Hence shredded plastic waste was added as stabilizer by $4,8,12$ and $16 \%$ by weight of binder Drain down characteristics was determined for mixes prepared for varying proportion RAP content of 10, 20 and 30\% using VG - 30 binders. The mixes prepared with Shredded plastic waste and RAP material fulfilled drain down conditions. However, drain down test was not conducted for RAP mixes prepared with Shredded plastic waste as existing combination has shown drain down value less than $0.3 \%$ weight of total mix. The drain down test results for above combinations is presented in Table 6 .

\subsection{Marshall Mix Design}

Marshall Mix design was carried out as per ASTM D6927-15[34]. Marshall Properties at Optimum Binder Content for different SMA Mixes are presented in Table 7 and 8 . The mixing and compaction temperature adopted for HMA and WMA mix is $160^{\circ} \mathrm{C}$ and $130^{\circ} \mathrm{C}, 130^{\circ} \mathrm{C}$ and $120^{\circ} \mathrm{C}$ respectively

Table 6. Drain down test results

\begin{tabular}{|c|c|c|c|c|c|c|c|c|c|}
\hline \multirow{2}{*}{ Particulars } & \multicolumn{3}{|c|}{} & \multicolumn{5}{c|}{ VG-30 with } \\
Shredded Waste Plastic (SWP)
\end{tabular}

Table 7. Marshall properties of SMA mixes for aggregates having EI+FI $=25$

\begin{tabular}{|c|c|c|c|c|c|c|c|}
\hline \multirow{2}{*}{ Particulars } & \multirow{2}{*}{$\begin{array}{c}\text { OBC }(\%) \\
\text { HMA } \\
\text { \&WMA }\end{array}$} & \multicolumn{2}{|c|}{ VMA (\%) } & \multicolumn{2}{|c|}{ Stability (kN) } & \multicolumn{2}{|c|}{ Flow (mm) } \\
\hline & & HMA & WMA & HMA & WMA & HMA & WMA \\
\hline Conventional SMA & 6.4 & 17.2 & 18.1 & 7.4 & 6.6 & 5.1 & 6.1 \\
\hline $\mathrm{SMA}+4 \% \mathrm{SWP}$ & 6.2 & 17.2 & 17.9 & 9.6 & 8.1 & 3.7 & 4.0 \\
\hline $\mathrm{SMA}+8 \% \mathrm{SWP}$ & 6.0 & 17.3 & 18.2 & 11.0 & 9 & 3.5 & 4.2 \\
\hline $\mathrm{SMA}+12 \% \mathrm{SWP}$ & 5.9 & 17.6 & 18.2 & 7.2 & 6.9 & 5.6 & 4.6 \\
\hline SMA+16\% SWP & 5.8 & 18.2 & 19.1 & 8.2 & 7 & 6 & 5.9 \\
\hline SMA+10\%RAP & 6.3 & 17.2 & 18.1 & 9.5 & 8.2 & 3.8 & 4.7 \\
\hline SMA+20\%RAP & 6.2 & 17.6 & 18.5 & 10.4 & 9 & 3.5 & 4.1 \\
\hline SMA+30\%RAP & 6.1 & 17.8 & 18.3 & 12.1 & 10.3 & 3.1 & 3.9 \\
\hline $\mathrm{SMA}+10 \% \mathrm{RAP}+4 \% \mathrm{SWP}$ & 6.1 & 17.4 & 18.1 & 10.8 & 9.2 & 3.5 & 4.4 \\
\hline $\mathrm{SMA}+10 \% \mathrm{RAP}+8 \% \mathrm{SWP}$ & 6.0 & 17.5 & 18.2 & 12.2 & 10 & 3.1 & 4.0 \\
\hline $\mathrm{SMA}+10 \% \mathrm{RAP}+12 \% \mathrm{SWP}$ & 5.9 & 18.0 & 18.9 & 7.9 & 7.1 & 5.7 & 3.8 \\
\hline $\mathrm{SMA}+10 \% \mathrm{RAP}+16 \% \mathrm{SWP}$ & 5.8 & 18.1 & 18.8 & 7.4 & 6.7 & 6.0 & 5.8 \\
\hline $\mathrm{SMA}+20 \% \mathrm{RAP}+4 \% \mathrm{SWP}$ & 5.9 & 17.2 & 18.1 & 11.6 & 10.2 & 3.4 & 4.2 \\
\hline $\mathrm{SMA}+20 \% \mathrm{RAP}+8 \% \mathrm{SWP}$ & 5.8 & 17.3 & 18.0 & 12.8 & 11.1 & 3 & 3.2 \\
\hline $\mathrm{SMA}+20 \% \mathrm{RAP}+12 \% \mathrm{SWP}$ & 5.8 & 18.0 & 18.9 & 8.7 & 7.2 & 6.1 & 3.3 \\
\hline $\mathrm{SMA}+20 \% \mathrm{RAP}+16 \% \mathrm{SWP}$ & 5.8 & 18.1 & 18.7 & 6.3 & 5.9 & 6.8 & 3.5 \\
\hline $\mathrm{SMA}+30 \% \mathrm{RAP}+4 \% \mathrm{SWP}$ & 5.9 & 17.2 & 17.9 & 12.9 & 11.4 & 3.1 & 3.1 \\
\hline $\mathrm{SMA}+30 \% \mathrm{RAP}+8 \% \mathrm{SWP}$ & 5.8 & 18.2 & 18.8 & 13.9 & 12.2 & 3.3 & 3.1 \\
\hline $\mathrm{SMA}+30 \% \mathrm{RAP}+12 \% \mathrm{SWP}$ & 5.8 & 18.0 & 18.7 & 9.2 & 8.3 & 6.7 & 5.2 \\
\hline $\mathrm{SMA}+30 \% \mathrm{RAP}+16 \% \mathrm{SWP}$ & 5.8 & 18.4 & 19.1 & 6.8 & 5.9 & 6.5 & 6.0 \\
\hline
\end{tabular}


Table 8. Marshall properties of SMA mixes for aggregates having EI+FI=35

\begin{tabular}{|c|c|c|c|c|c|c|c|}
\hline \multirow{2}{*}{ Particulars } & \multirow{2}{*}{$\begin{array}{c}\text { OBC \%) } \\
\text { HMA \& WMA }\end{array}$} & \multicolumn{2}{|c|}{ VMA $(\%)$} & \multicolumn{2}{|c|}{ Stability (kN) } & \multicolumn{2}{|c|}{ Flow (mm) } \\
\hline & & HMA & WMA & HMA & WMA & HMA & WMA \\
\hline Conventional SMA & 6.6 & 18.6 & 19.0 & 6.8 & 6.7 & 5 & 6.0 \\
\hline $\mathrm{SMA}+4 \% \mathrm{SWP}$ & 6.4 & 18.4 & 19.7 & 8.3 & 8.9 & 3.5 & 3.9 \\
\hline $\mathrm{SMA}+8 \% \mathrm{SWP}$ & 6.2 & 19.2 & 18.8 & 9.5 & 10.5 & 3.2 & 4.0 \\
\hline SMA+12\%SWP & 6.0 & 20.2 & 19.1 & 6.7 & 7.3 & 5.6 & 4.5 \\
\hline SMA+16\% SWP & 5.9 & 20.0 & 19.4 & 6.5 & 7.3 & 5.9 & 5.7 \\
\hline $\mathrm{SMA}+10 \% \mathrm{RAP}$ & 6.5 & 18.9 & 19.1 & 9.0 & 8.6 & 3.8 & 4.6 \\
\hline $\mathrm{SMA}+20 \% \mathrm{RAP}$ & 6.4 & 19.4 & 19.2 & 9.9 & 9.1 & 3.2 & 4.0 \\
\hline $\mathrm{SMA}+30 \% \mathrm{RAP}$ & 6.3 & 19.6 & 19.4 & 11.1 & 11.0 & 3 & 3.8 \\
\hline $\mathrm{SMA}+10 \% \mathrm{RAP}+4 \% \mathrm{SWP}$ & 6.3 & 19.1 & 19.8 & 10.7 & 9.8 & 3.4 & 4.2 \\
\hline $\mathrm{SMA}+10 \% \mathrm{RAP}+8 \% \mathrm{SWP}$ & 6.2 & 19.3 & 19.1 & 12.0 & 10.9 & 3.1 & 3.9 \\
\hline $\mathrm{SMA}+10 \% \mathrm{RAP}+12 \% \mathrm{SWP}$ & 6.0 & 19.8 & 19.2 & 6.6 & 7.2 & 5.5 & 3.7 \\
\hline $\mathrm{SMA}+10 \% \mathrm{RAP}+16 \% \mathrm{SWP}$ & 5.9 & 20.0 & 19.5 & 6.7 & 6.5 & 5.8 & 5.6 \\
\hline $\mathrm{SMA}+20 \% \mathrm{RAP}+4 \% \mathrm{SWP}$ & 6.0 & 18.9 & 20.2 & 10.5 & 10.5 & 3.3 & 4.1 \\
\hline $\mathrm{SMA}+20 \% \mathrm{RAP}+8 \% \mathrm{SWP}$ & 5.9 & 19.0 & 19.0 & 10.9 & 11.3 & 2.9 & 3.0 \\
\hline $\mathrm{SMA}+20 \% \mathrm{RAP}+12 \% \mathrm{SWP}$ & 5.9 & 19.8 & 19.2 & 8.0 & 7.9 & 6.1 & 3.2 \\
\hline $\mathrm{SMA}+20 \% \mathrm{RAP}+16 \% \mathrm{SWP}$ & 5.9 & 19.9 & 20.4 & 5.9 & 5.7 & 6.7 & 3.5 \\
\hline $\mathrm{SMA}+30 \% \mathrm{RAP}+4 \% \mathrm{SWP}$ & 6.0 & 18.9 & 18.2 & 10.8 & 11.7 & 3 & 3.0 \\
\hline $\mathrm{SMA}+30 \% \mathrm{RAP}+8 \% \mathrm{SWP}$ & 5.9 & 19.8 & 19.0 & 12 & 12.6 & 3.2 & 2.9 \\
\hline $\mathrm{SMA}+30 \% \mathrm{RAP}+12 \% \mathrm{SWP}$ & 6.0 & 20.0 & 19.3 & 9.1 & 8.4 & 6.6 & 5.0 \\
\hline $\mathrm{SMA}+30 \% \mathrm{RAP}+16 \% \mathrm{SWP}$ & 6.2 & 20.2 & 20.8 & 6.0 & 5.9 & 7.1 & 5.8 \\
\hline
\end{tabular}

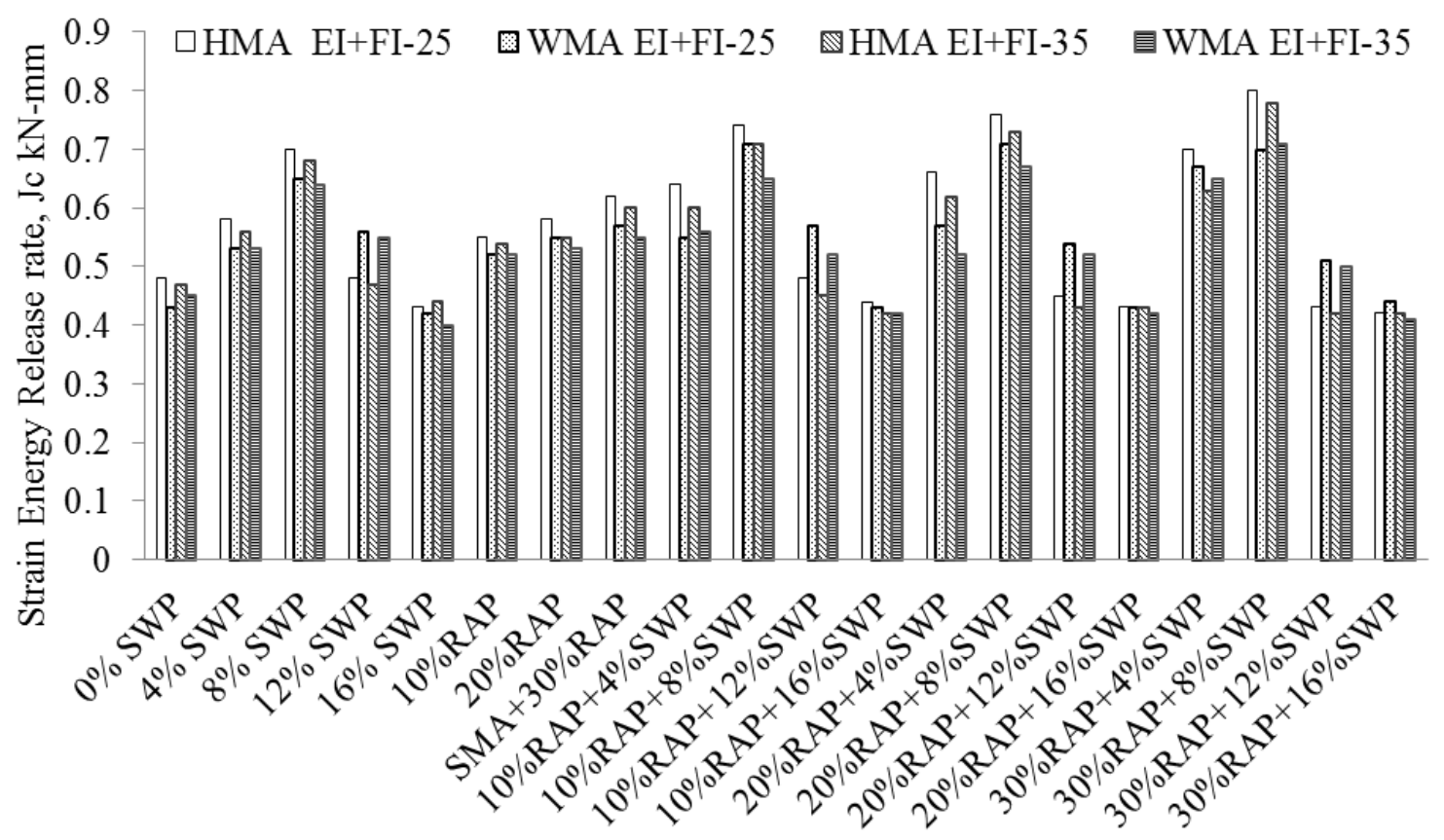

Figure 2. Critical energy release rate/cracking resistance of SMA mixes, JckN-mm 


\subsection{Semi-circular Bending Test}

The test is conducted to determine fatigue cracking of SMA mixes in terms of critical strain energy, Jc. The Jc values obtained for different combinations of RAP and SWP in SMA mixes are shown in Figure 2.

\subsubsection{Sample preparation}

The semi-circular bending (SCB) specimen was obtained by slicing modified Marshall Specimens shown in Figure 3 of dimension $150 \mathrm{~mm}$ diameter and $112 \mathrm{~mm}$ height. The numbers of blows were adjusted to achieve target air void level of $6.5 \pm 5 \%$. Then the specimen is cut along its central axis into two equal semi-circular shapes having a thickness of $57 \pm 1 \mathrm{~mm}$. Three nominal notch depths of 25,32 and $38 \mathrm{~mm}$ are cut along symmetrical axis of each semi-circular specimen with a tolerance of $\pm 1 \mathrm{~mm}$. The width of notch cut specimen was $<3.5 \mathrm{~mm}$. Sample specimen is shown in Figure 4.

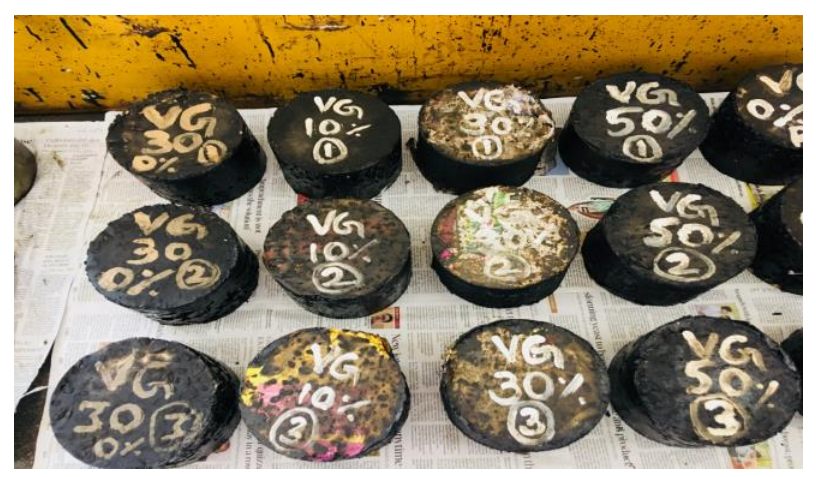

Figure 3. Modified Marshall specimens

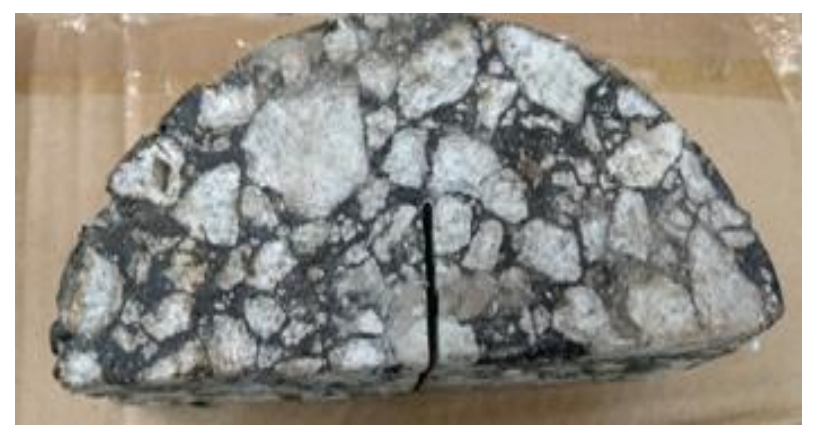

Figure 4. Semi circular bending specimen

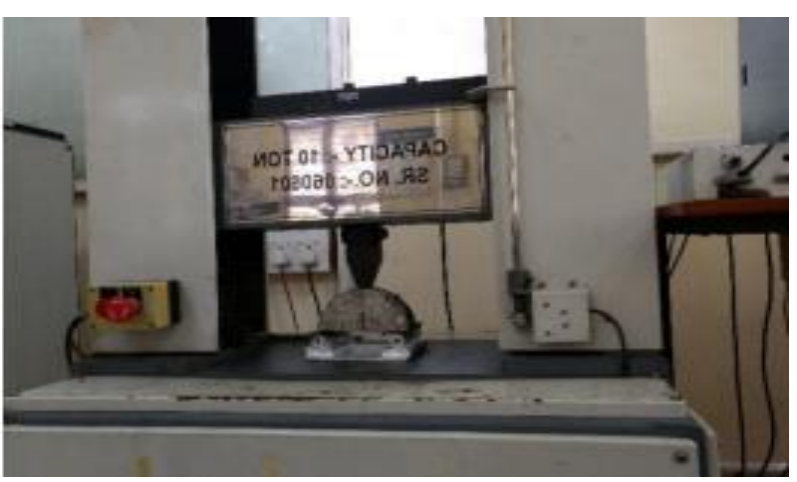

Figure 5. Testing for cracking resistance

\subsubsection{Experimental Procedure}

The cracking resistance was determined at $25^{\circ} \mathrm{C}$ using SCB test as per ASTM D8044-16. A semi-circular specimen is loaded monotonically until fracture failure occurs under a constant rate of deformation of 0.05 $\mathrm{mm} /$ minute. The load and deformation are continuously recorded and are used to compute the strain energy for notch depth of 25,32 and $38 \mathrm{~mm}$. SCB sample and its setup in universal testing machine are shown in Figure 5.

The critical strain energy release rate ( $\mathrm{J}$ - integral) is determined using Equation 2.

$$
\mathrm{JC}=\frac{-1}{\mathrm{~b}}\left(\frac{\mathrm{dU}}{\mathrm{da}}\right)(2)
$$

Where:

$\mathrm{Jc}=$ critical strain energy release rate $(\mathrm{kN}-\mathrm{mm})$; $\mathrm{b}=$ sample thickness (m); a=notch depth (m); U=strain energy to failure $\mathrm{dU} / \mathrm{da}=$ change of strain energy with notch depth $(\mathrm{kN} / \mathrm{m})$.

\section{Results and Discussions}

\subsection{Volumetric Properties}

\subsubsection{Aggregate Shape}

From Table 7 and 8 , it is observed that, SMA mix prepared with aggregates having $\mathrm{EI}+\mathrm{FI}=25$ shown better stability compared to aggregates having $\mathrm{EI}+\mathrm{FI}=35$. Due to the presence of cubical aggregates, better interlocking takes places compared to irregular shape aggregates which are more susceptible to breaking. The optimum binder content increases for the mix having aggregates $\mathrm{EI}+\mathrm{FI}=35$. This may due to aggregates having $\mathrm{EI}+\mathrm{FI}=35$ have more surface area and requires additional bitumen to coat around aggregate particles.

\subsubsection{Shredded Waste Plastic}

The optimum binder content decreases with addition of shredded waste plastic to conventional SMA and RAP SMA mixes. This is due to waste plastic coats around aggregates thereby reducing porosity in aggregates. The increase in Marshall stability was observed up to $8 \%$ SWP content for HMA mix and $12 \%$ for WMA mix and decreased with further addition of SWP content.

\subsubsection{WMA}

The Marshall stability increased with addition of RAP increased for both HMA and WMA mixes. Similar trend was observed for Asphaltic concrete HMA mix with the addition of RAP [35].This may be due to presence of aged binder in RAP material which makes mix better stability compared to conventional SMA.WMA mixes exhibited lesser resistance to Marshall stability compared to HMA mixes, addition of WMA additive makes mix less ageing thereby less stiffness. However, all these mixes satisfied the requirements of Indian Roads Congress-SP 79-2008 i.e., drain down less than $0.3 \%$, VMA above $17 \%$. 


\subsection{Cracking Resistance}

(iii).

\subsubsection{Effect of Aggregate Shape on J- Integral}

From Table 1 and 2, coarse aggregates having EI+FI=25, sphericity varied from $0.69-0.72$ indicating aggregates are Equiaxial or near to cubical/angular shape as per Zingg diagram. Similarly, shape of aggregates is oblate/prolate or more flaky/elongated for aggregates having $\mathrm{EI}+\mathrm{FI}=35$. From Figure 2, mix containing coarse aggregate of $\mathrm{EI}+\mathrm{FI}=25$ showed increase in $\mathrm{J}$-Integral value by $5 \%$ compared to mix containing coarse aggregate $\mathrm{EI}+\mathrm{FI}=35$ for all combinations. However, increase was found to be insignificant as both combinations met ASTM specifications. This may be due to both shapes of aggregate fulfilled VMA and $\mathrm{VCA}_{\mathrm{DRY}} / \mathrm{VCA}_{\mathrm{MIX}}$ requirements as per MoRTH (2013).

\subsubsection{Effect of RAP on J-Integral}

The cracking resistance of SMA mixes is determined for varying proportions of RAP content i.e., 0, 10, 20 and 30\%. Based on the results shown in Figure 2, Jc value increased from $0.54 \mathrm{kN}-\mathrm{mm}$ to $0.63 \mathrm{kN}-\mathrm{mm}$ with the addition of RAP due to increase in stiffness of mix.

\subsubsection{Combined effect of RAP and SWP on J- Integral}

In hot SMA mix, for RAP content of 10, 20 and 30\% having shredded plastic waste dosage of 4 and $8 \%$, the obtained Jc value meets requirements. However, for RAP content of 10, 20 and $30 \%$ having shredded plastic waste dosage of 12 and $16 \%$ resulted in decrease in Jc value which is below the requirements of ASTM. However, addition of shredded plastic waste up to $8 \%$ to RAP mix improves elasticity and better deformability.

\subsubsection{Combined Effect of RAP and Shredded Plastic Waste and Addition of Warm Mix Additive on J-Integral}

From Figure 2, it can be inferred that up to dosage of $12 \%$ shredded plastic waste in SMA specimens with WMA additive resulted in Jc value which fulfills ASTM requirements. However, increase in dosage of shredded plastic waste beyond $12 \%$ resulted in decrease in Jc values. Since mixing is done at lower temperature, only partial SWP will be absorbed by RAP binder.

\section{Conclusions}

From present study it is observed that

(i). The mix containing coarse aggregate of $\mathrm{EI}+\mathrm{FI}=25$ showed increase in J-Integral value by $5 \%$ compared to mix containing coarse aggregate $\mathrm{EI}+\mathrm{FI}=35$ for all combinations .

(ii). Addition of RAP in SMA mixes showed better resistance to cracking due to increased in stiffness in mix.
Addition of shredded plastic waste for hot RAP-SMA mixes showed better resistance for cracking than mix prepared with warm mix additive.

For SMA mixes prepared with addition of shredded waste plastic indicated better cracking resistance up to $8 \%$, decrease in Jc was observed for mixes prepared using WMA additive.

(v). The optimal dosage of shredded plastic waste for RAP-SMA specimens without WMA additive was found to be $8 \%$ and same found to be $12 \%$ for specimens prepared with WMA additive.

(vi). Studies indicate waste plastic can be utilized in warm asphalt mixes and dosage can be increased compared to hot mixes.

\section{REFERENCES}

[1] Witczak, M. W., Kaloush, K., Pellinen, T., Basyouny, M. E., and Quintus, H. V., "Simple performance test for superpave mix design." NCHRP Rep. 465, National Cooperative Highway Research Program, National Research Council, Washington, DC, 2002.

[2] Maupin Jr, G.W., "Effect of particle shape and surface texture on the fatigue behavior of asphaltic concrete", Highway Research Record, No. 313, 1970.

[3] Arasan, S., Yenera, E., Hattatoglu, F., Hinislioglua, S., and Akbuluta, S., "Correlation between shape of aggregate and mechanical properties of asphalt concrete: Digital image processing approach". Road Materials and Pavement Design, Vol. 12, No.2, 2011, pp. 239-262, http://dx.doi.org/10.1080/14680629.2011.9695245.

[4] Barrett, P. J., "The shape of rock particles, a critical review" Sedimentology., Vol. 27,1980, p. 291- 303.

[5] Masad, E., and Button, J. W., "Unified imaging approach for measuring aggregate angularity and texture" Comput. Aided Civ. Infrastruct. Eng., Vol. 15, No. 4, 2004, pp.273280, https://doi.org/10.1111/0885-9507.00191.

[6] Iuri, S. Bessa., Verônica, T. F., Castelo, Branco., Soares, J. B., and José. A., and Nogueira, Neto., "Aggregate shape properties and their influence on the behavior of hot-mix asphalt", J. Mater. Civ. Eng., Vol. 27, No. 7, 2015, http://dx.doi.org/10.1061/ (ASCE) MT.1943-5533.000118 1 .

[7] Souliman, M "Integrated predictive model for healing and fatigue endurance limit for asphalt concrete". 2012, Arizona: Arizona State University.

[8] Arasan, S., Yenera, E., Hattatoglu, F., Hinislioglua, S., and Akbuluta, S., "Correlation between shape of aggregate and mechanical properties of asphalt concrete: Digital image processing approach". Road Materials and Pavement Design, Vol. 12, No. 2, 2011, pp. 239-262, http://dx.doi.org/10.1080/14680629.2011.9695245.

[9] Huang, E. Y., and Grisham, D. A., "Effect of geometric characteristics of aggregates on the fatigue response of bituminous paving mixtures", Fatigue of compacted 
bituminous aggregate mixtures, 1972, pp.145-160, ASTM International, West Conshohocken, PA.

[10] Bose, S., Kumar, G., and Sharma, G., "Performance characteristics of bituminous mixes modified by waste plastic bags". Highway Research Bulletin, Indian roads congress, Vol. 71, 2005, pp. 1-10

[11] Ananna Ahmed, Syeda. R. Aziz., M, Hossain., and Blair Heptig, "Evaluation of semi circular bending test for assessing cracking potential of superpave mixture with high reclaimed asphalt content" Presented at International Airfield and Highway Pavements Conference 2015Innovative and Cost-Effective Pavements for a Sustainable Future, Miami, Florida, June 7-10, 2015, http://dx.doi.org/10.1061/9780784479216.001.

[12] Vasudevan, R., Saravanavel, S., Rajasekaran, S., and Thirunakkarasu, D, "Utilization of waste plastics in construction of flexible pavement" Indian Highways, Vol.34, No.7, 2006, pp.5-20.

[13] Mohamed Elkashefa, R. Christopher Williamsa., Eric Cochranb.2018. "Investigation of fatigue and thermal cracking behavior of rejuvenated reclaimed asphalt pavement binders and mixtures". Int J Fatigue, 108, 90-95,

[14] West, R "Phase IV NCAT pavement test track findings, National Center for Asphalt Technology, Report Number NCAT 12-10, 2012 Auburn: Alabama, USA.

[15] Willis, J. R., Turner, P., Padula, F. d. G., Tran, N., \& Julian, "Effects of changing virgin binder grade and content on high reclaimed asphalt pavement mixture properties. Transportation Research Record: Journal of the Transportation Research Board, 2013, 2371, 66-73.

[16] AmbikaBehl and Satish Chandra "Aging Characteristics of Warm-Mix Asphalt Binders,Journal of Materials in Civil Engineering, ASCE, Vol. 29, Issue 10. 2007.

[17] Ali Mokhtari and Fereidoon Moghadas Nejad "Comparative Study on Performance of Wax-Modified and Typical SMA Mixtures", Journal of Materials in Civil Engineering, ASCE Journal, Vol 25 (3) 2013.

[18] Panda, M. and Mazumdar, M. (2002). "Utilization of reclaimed polyethylene in bituminous paving mixes." Journal of Materials in Civil Engineering, 14(6), 527-530.

[19] Hinislioglu, S. and Ag ar, E 2004. "Use of waste high density polyethylene as bitumen modifier in asphalt concrete mix." Materials Letters, 58(3-4), 267-271.

[20] Rahman, M.N., Ahmeduzzaman, M., Sobhan, M.A. and Ahmed, T.U. (2013). "Performance evaluation of waste polyethylene and PVC on hot asphalt mixtures." American Journal of Civil Engineering and Architecture, 1(5), 97-102.

[21] Ahmadinia, E., Zargar, M., Karim, M.R., Abdelaziz, M. and Ahmadinia, E. (2012). "Performance evaluation of utilization of waste Polyethylene Terephthalate (PET) in stone mastic asphalt." Construction and Building Materials, 36, 984-989.

[22] Ahmadinia, E., Zargar, M., Karim, M.R., Abdelaziz, M. and Shafigh, P. (2011). "Using waste plastic bottles as additive for Stone Mastic Asphalt." Materials and Design, 32(10), 4844-4849.
[23] Mohammad, L., Abadie, C., Gokmen, R. and Puppala, A. (2000). "Mechanistic evaluation of hydrated lime in hot-mix asphalt mixtures." Transportation Research Record: Journal of the Transportation Research Board, 1723, 26-36.

[24] Mohammad, L., Zhang, X., Huang, B. and Tan, Z. (1999). "Laboratory performance evaluation SMA, CMHB and dense graded asphalt mixtures." Journal of the Association of Asphalt Paving Technologists, 68, 252-283.

[25] Singh, D., Ashish, P.K., and Chitragar,S.F., "Laboratory performance of recycled asphalt mixes containing wax and chemical based warm mix additives using Semi circular bending and tensile strength ratio test", J. Constr. Build. Mater Vol.158, pp.1003-1014 https://doi.org/10.1016/j.con buildmat.2017.10.080

[26] Souza, T.L., Kim, Y.R., Souza, F.V., and Castro, L.S., "Experimental testing and finite-element modeling to evaluate the effects of aggregate angularity on bituminous mixture performance", J. Mater. Civ. Eng., Vol.24, No.4, 2012, pp.249-258, https://doi.org/10.1061/(ASCE)MT.194 3-5533.0000386.

[27] ASTM D8044-16.Standard Test Method for Evaluation of Asphalt Mixture Cracking Resistance using the Semi-Circular Bend Test (SCB) at Intermediate Temperatures. ASTM International, West Conshohocken, PA, 2016.

[28] Krumbein, W. C., Pettijohn F. J., "Manual of sedimentary petrology", Appleton Century Crofts Inc., New York, 1938, https://archive.org/details/in.ernet.dli.2015.476132(accesse d 20 July.2018).

[29] Huang, B., Chen, X., Shu, X., Masad, Mahmoud, E, "Effects of coarse aggregate angularity and asphalt binder on laboratory-measured permanent deformation properties of HMA". International Journal of Pavement Engineering. Vol.10. No.9, 2009, pp.19-28. https://doi.org/10.1080/102 98430802068915 .

[30] IS 73 (2013). "Paving bitumen specifications." Fourth Revision,Indian Standards Institution, New Delhi, India.

[31] ASTM D2172M-11. "Standard Test Methods for Quantitative Extraction of Bitumen From Bituminous Paving Quantitative Extraction of Bitumen From Bituminous Paving Mixtures". ASTM International, West Conshohocken, PA, 2016.

[32] MoRTH-Ministry of Road Transport and Highways. (2013). "Specifications for Road and Bridge Works, $5^{\text {th }}$ Revision." Indian Road Congress, New Delhi, India.

[33] IRC SP 79 (2008). "Tentative specifications for Stone Matrix Asphalt." Special Publication of Indian Roads Congress, IRC, New Delhi, India.

[34] ASTM 6927-15. "Standard Test Method for Marshall Stability and Flow of Asphalt Mixtures". ASTM International, West Conshohocken, PA, 2016.

[35] Sri. Sunarjono, Nurul. Hidayati, Mochamad Rivai Wisnu Ardianto, Alfia Magfirona, "Analysis of AC-WC Design Material Using Reclaimed Asphalt Pavement," Civil Engineering and Architecture, Vol. 8, No. 3, pp. 274 - 280, 2020. DOI: $10.13189 /$ cea.2020.080310 